\title{
High specificity but low sensitivity of mutation-specific antibodies against EGFR mutations in non-small-cell lung cancer
}

\author{
Anna-Louise Bondgaard ${ }^{1}$, Estrid Høgdall ${ }^{2}$, Anders Mellemgaard ${ }^{3}$ and Birgit G Skov ${ }^{1}$ \\ ${ }^{1}$ Department of Pathology, Copenhagen University Hospital, Rigshospitalet, Copenhagen, Denmark; \\ ${ }^{2}$ Department of Pathology, Molecular Unit, Herlev University Hospital, Copenhagen, Denmark and \\ ${ }^{3}$ Department of Medical Oncology, Herlev University Hospital, Copenhagen, Denmark
}

\begin{abstract}
Determination of epidermal growth factor receptor (EGFR) mutations has a pivotal impact on treatment of non-small-cell lung cancer (NSCLC). A standardized test has not yet been approved. So far, Sanger DNA sequencing has been widely used. Its rather low sensitivity has led to the development of more sensitive methods including real-time PCR (RT-PCR). Immunohistochemistry with mutation-specific antibodies might be a promising detection method. We evaluated 210 samples with NSCLC from an unselected Caucasian population. Extracted DNA was analyzed for EGFR mutations by RT-PCR (Therascreen EGFR PCR kit, Qiagen, UK; reference method). For immunohistochemistry, antibodies against exon19 deletions (clone 6B6), exon21 mutations (clone 43B2) from Cell Signaling Technology (Boston, USA) and EGFR variantllI (clone 218C9) from Dako (Copenhagen, DK) were applied. Protein expression was evaluated, and staining score (multipum of intensity (graded $0-3)$ and percentages $(0-100 \%)$ of stained tumor cells) was calculated. Positivity was defined as staining score $>0$. Specificity of exon 19 antibody was $98.8 \%(95 \%$ confidence interval $=95.9-99.9 \%)$ and of exon 21 antibody $97.8 \%(95 \%$ confidence interval $=94.4-99.4 \%)$. Sensitivity of exon 19 antibody was $63.2 \%(95 \%$ confidence interval $=38.4-83.7 \%)$ and of exon21 antibody was $80.0 \%(95 \%$ confidence interval $=44.4-97.5 \%)$. Seven exon19 and four exon21 mutations were false negatives (immunohistochemistry negative, RT-PCR positive). Two exon19 and three exon21 mutations were false positive (immunohistochemistry positive, RT-PCR negative). One false positive exon21 mutation had staining score 300. The EGFR variantIII antibody showed no correlation to EGFR mutation status determined by RT-PCR or to EGFR immunohistochemistry. High specificity of the mutation-specific antibodies was demonstrated. However, sensitivity was low, especially for exon19 deletions, and thus these antibodies cannot yet be used as screening method for EGFR mutations in NSCLC. Refinement of sensitivity for the mutation-specific antibodies is warranted to improve molecular diagnosis using EGFR immunohistochemistry.

Modern Pathology (2014) 27, 1590-1598; doi:10.1038/modpathol.2014.67; published online 25 April 2014
\end{abstract}

Keywords: EGFR mutations; immunohistochemistry; mutationmutation-specific antibody; NSCLC; sensitivity; specificity

Presence of activating mutations in epidermal growth factor receptor (EGFR) predicts response to EGFR tyrosine kinase inhibitors in patients with non-small-cell lung cancer (NSCLC). Therefore, EGFR mutational status should be determined before initial treatment. ${ }^{1-8}$ About $90 \%$ of activating EGFR mutations is deletions of exon19 or point

Correspondence: Dr A-L Bondgaard, MD, Department of Pathology, Copenhagen University Hospital, Rigshospitalet, Bispebjerg Bakke 23, section 19b, 2400 Copenhagen, Denmark.

E-mail: anloudk@yahoo.com

Received 10 December 2013; revised 20 February 2014; accepted 25 February 2014; published online 25 April 2014 mutations of exon21. Other important mutations are insertions in exon20 (T790M), which predicts resistance to EGFR tyrosine kinase inhibitors, and activating mutations of exon18 (G719A-C) and exon21 (L861Q). Several other EGFR mutations have been reported, but their clinical significance is yet unknown. Mutation rate in adenocarcinomas in East Asian patients are $20-50 \%{ }^{9}$ and $5-15 \%$ in Western European patients depending on whether selected $^{9}$ or unselected ${ }^{10-13}$ patients are tested.

No gold standard method for the detection of EGFR mutations in NSCLC is approved. Previously, Sanger DNA sequencing has been widely used, but its disadvantages, primarily its low sensitivity 
(requirement of $40-50 \%$ mutant DNA in samples), ${ }^{9}$ has before led to the development of more sensitive detecting methods including real-time quantitative PCR (RT-PCR). However, this method is relatively expensive, time consuming, and not incorporated in routine diagnostic procedures in many departments of pathology. In contrast, immunohistochemistry has lower costs, shorter turnaround time, and is available in the majority of laboratories. For these reasons, mutation-specific antibodies might be a relevant alternative for determining EGFR status in NSCLC. ${ }^{14-22}$ So far, no standardized protocol exists for EGFR immunohistochemistry in these tumors. ${ }^{9,23,24}$

The aim of this study was to determine sensitivity and specificity of mutation-specific antibodies in detection of EGFR mutations in an unselected cohort of Caucasian patients with NSCLC. We hypnotized that the antibodies against EGFR mutations might be an alternative method for identifying patients with EGFR mutations, who could benefit from EGFR tyrosine kinase inhibitors.

\section{Materials and methods}

This study was designed as a nested case-control study including 210 NSCLC samples from a large Caucasian population-based study of the incidence of EGFR mutations. ${ }^{13}$ Briefly, the incidence study included 1256 consecutive tumor samples from a well-defined geographical area (The Capital Region of Denmark). DNA was extracted from histological or cytological tumor samples and analyzed for EGFR mutations by Therascreen EGFR PCR kit (Qiagen, Manchester, UK). By the time of planning the present study, 36 mutation-positive samples were found.

Histological and clot material from cytological samples (but not smears) were used for immunohistochemistry. By preliminary $\mathrm{HE}$ examination of the tumor samples included in the study, the optimal tissue or clot block was selected. For each patient, we aimed to test immunohistochemistry on the same material as used for RT-PCR. If material from same block was not available (because of no tumor left after material for RT-PCR was cut), material from different blocks from same location were chosen if available. If different samples from same location were not available, material from different locations was used. For cytological samples, the same hierarchical selection was applied: preferably immunohistochemistry and RT-PCR from the same block, if not possible, immunohistochemistry was done on block, whereas RT-PCR was done on slide from same location. If not available, then immunohistochemistry was done on block, whereas RT-PCR was done on slide from different locations.

\section{EGFR Immunohistochemistry}

Formalin-fixed, paraffin-embedded tissues were cut into 3- to 4- $\mu \mathrm{m}$-thick sections. Deparaffinization was performed in PT LINK (Dako, DK) in 70 min. Epitope retrieval was performed by FLEX TRS High mixed (pH 9.0; Dako, DK). 3\% Hydrogen peroxide was used to block endogenous peroxidase. Preliminary antibody dilution tests were performed on blocks with known mutational status. Antibody dilutions tested were $1: 50,1: 100$, and 1:150 according to the literature. ${ }^{14-22}$ The included sections were incubated with primary monoclonal rabbit antibodies against exon19 deletions (clone 6B6, Cell Signaling Technology, Boston, MA, USA) diluted to 1:150 (optimal dilution), against point mutation of exon21, L858R (clone 43B2, Cell Signaling Technology) diluted to 1:100 amplified by linker (optimal dilution), and with primary monoclonal mouse antibody against EGFR variantIII (clone 218C9, EGFR pharmDx kit, Dako, DK) in 20 min.

The antibodies were visualized according to the standardized protocol of EnVision FLEX + system (Dako, DK) and diaminobenzidine was used as chromogen in an automated immunostainer (DakoLink 48, Dako, DK). The sections were counterstained with hematoxylin. Positive controls included five cell suspensions of mutated exon19 (H1650-988, Cell Signaling Technology) and mutated exon21 (H1975988, Cell Signaling Technology) and two blocks of known mutational status. For negative controls, primary antibodies were replaced by phosphate buffer.

\section{Scoring of Immunohistochemistry}

Percentage (0-100\%) and intensity of stained malignant epithelial tumor cells were registered. Intensity was graded 0-3 ( $0=$ no membrane and/or cytoplasmic staining of the malignant epithelial tumor cells evaluated in $\times 40$ objective magnification, $1=$ faint membrane and/or cytoplasmic staining of malignant epithelial tumor cells seen in $\times 40$ objective magnification, 2 = weak/moderate membrane and/or cytoplasmic staining of the malignant epithelial tumor cells seen in $\times 10$ to $\times 20$ objective magnification, $3=$ strong membrane and/or cytoplasmic staining of the malignant epithelial tumor cells seen in $\times 2$ to $\times 4$ objective magnification). ${ }^{25}$ Staining score $=$ (percentage of intensity $1 \times$ intensity 1$)+$ (percentage of intensity $2 \times$ intensity 2 ) + (percentage of intensity3 $\times$ intensity3) was calculated (scale 0-300). Positivity of EGFR immunohistochemistry was defined as staining score $>0$.

The samples were evaluated by ALB and BGS. Samples having equivocal staining, nonspecific staining, or staining artifacts were re-analyzed by both evaluators and decisions on percentage (0$100 \%$ ) and intensity of stained malignant epithelial tumor cells were registered.

\section{EGFR Mutational Analysis}

The Therascreen EGFR PCR Kit (Qiagen) was applied as RT-PCR analysis. It is a combined technology 
using amplified refractory mutation system (ARMS, AstraZeneca, Macclesfield, UK) and fluorescent signaling system (Scorpions, Qiagen). It detects 29 mutations from exon18-21 with sensitivity of 1\%: 3 point mutations of exon18 (G719X), 19 mutations of exon19 (including deletion E746-A750), 2 point mutations of exon20 (S768I, T790M), 3 exon20 insertions, and 2 point mutations of exon21 (L861Q, L858R). For the assay, representative formalin-fixed, paraffin-embedded tissues were selected. Three sections of $10-\mu \mathrm{m}$-thick tumor tissue were cut and if necessary macro-dissected in order to ensure high percentage of tumor cells. Briefly, tissue sections were treated once with xylene, followed by one wash in ethanol. The pellet was resuspended in ATL buffer (tissue lysis buffer) and treated with proteinase-K overnight at $56^{\circ} \mathrm{C}$. After inactivation of proteinase-K by heating, DNA was extracted using QIAamp DNA Mini Kit (Qiagen). If the optimal specimen from a patient was a smear, the Mai Giemsa Grunwald-stained material was used for EGFR analysis without de-staining. Extracted DNA was analyzed by Therascreen EGFR PCR Kit (Qiagen) by EH according to the manufacturer's instructions.

\section{Statistics}

Data management and analysis were done in JMP version 9. Specificity and sensitivity of the mutationspecific antibodies were calculated (JMP version 9).

\section{Results}

\section{Sample Characteristics}

Among the 210 enrolled samples, 19 were excluded (13 excluded due to no tumor cells were left and 6 did not fulfilled the inclusion criteria) leaving 191 specimens available for immunohistochemistry and RT-PCR. The clinicopathological characteristics of the included samples were summarized in Table 1.

One hundred and twenty-nine histological and sixty-two cytological samples were included. Of the paired histological samples, 108 had material from the same block used for immunohistochemistry as well as for RT-PCR. Six paired samples had material from different blocks from same location used for immunohistochemistry and RT-PCR and fifteen were from same location but it was not possible to determine whether immunohistochemistry and RTPCR were performed on same block or different block from same location.

For paired samples in which EGFR mutation status was determined by RT-PCR on cytological (either clots or smeared) material and immunohistochemistry was determined on cytological or histological material, 44 specimens had same (clot) block used for immunohistochemistry and RT-PCR. Two had different (clot) blocks from same location
Table 1 Clinicopathological characteristic of the 191 included NSCLC

\begin{tabular}{|c|c|c|}
\hline \multicolumn{2}{|l|}{ Sample demographics } & No. samples \\
\hline \multicolumn{2}{|l|}{ Total } & 191 \\
\hline \multicolumn{3}{|l|}{ Diagnosis } \\
\hline \multicolumn{2}{|l|}{ Adenocarcinoma } & 112 \\
\hline \multicolumn{2}{|l|}{ Squamous cell carcinoma } & 52 \\
\hline \multicolumn{2}{|l|}{ Large cell neuroendocrine tumor } & 7 \\
\hline \multicolumn{2}{|c|}{$\begin{array}{l}\text { Other (large-cell carcinoma, sarcomatoid } \\
\text { carcinoma, salivary gland tumor, karcinoid, } \\
\text { not otherwise specified, combined) }\end{array}$} & 20 \\
\hline \multicolumn{3}{|c|}{ Samples types for EGFR immunohistochemistry } \\
\hline \multicolumn{2}{|c|}{ Histological } & 129 \\
\hline \multicolumn{2}{|l|}{ Cytological } & 62 \\
\hline \multicolumn{3}{|l|}{$\begin{array}{l}\text { Number of malignant epithelial cells } \\
\text { in material for immunohistochemistry }\end{array}$} \\
\hline \multicolumn{2}{|l|}{$\begin{array}{l}\text { in material for immunonistocnemistry } \\
\leq 100\end{array}$} & 11 \\
\hline \multicolumn{2}{|l|}{$100-400$} & 57 \\
\hline \multicolumn{2}{|l|}{$>400$} & 123 \\
\hline \multicolumn{3}{|l|}{ Smoking status } \\
\hline \multicolumn{2}{|l|}{ Never smoker } & 18 \\
\hline \multirow{2}{*}{\multicolumn{2}{|c|}{ Ex-smoker }} & 78 \\
\hline & & 94 \\
\hline \multicolumn{2}{|l|}{ Not available } & 1 \\
\hline Block specification & Histological & Cytological \\
\hline $\begin{array}{l}\text { Same block for EGFR } \\
\text { immunohistochemistry and RT-PCR }\end{array}$ & 108 & 44 \\
\hline $\begin{array}{l}\text { Different block, same location for EGFR } \\
\text { immunohistochemistry and RT-PCR }\end{array}$ & 6 & 2 \\
\hline $\begin{array}{l}\text { Same location but not specified if same } \\
\text { block or different block from same } \\
\text { location for EGFR } \\
\text { immunohistochemistry and RT-PCR }\end{array}$ & 15 & 0 \\
\hline $\begin{array}{l}\text { EGFR immunohistochemistry from } \\
\text { block, RT-PCR on slide, same location }\end{array}$ & 0 & 16 \\
\hline
\end{tabular}

Abbreviations: EGFR, epidermal growth factor receptor; NSCLC, non-small-cell lung cancer; RT-PCR, real-time quantitative PCR.

used for immunohistochemistry and RT-PCR. In 16 paired samples, (clot) block was used for immunohistochemistry and smeared material from the same location was used for RT-PCR.

\section{Mutations Detected by EGFR Immunohistochemistry and RT-PCR}

Mutations detected by EGFR immunohistochemistry and RT-PCR were summarized in Tables 2 and 3. RTPCR detected 19 exon19 deletions, 12 exon21 mutations, 2 exon 18 mutations, and 3 exon 20 mutations. Of the exon19 deletions detected by RT-PCR, twelve were detected by the exon19 antibody. Of the exon21 mutations detected by RT-PCR, eight (L858R mutations) were detected by the exon21 antibody. EGFR immunohistochemistry detected five mutations, which were RT-PCR wild type (two exon19 deletions and three exon21 mutations). 
Table 2 Overview of EGFR exon19 mutations by EGFR IHC and RT-PCR

\begin{tabular}{|c|c|c|c|c|c|c|c|c|}
\hline & \multicolumn{8}{|c|}{$R T-P C R$} \\
\hline & Exon 19del & Exon 20ins & $G 719 X$ & $L 858 R$ & $L 861 Q$ & S768I & $W T$ & Total \\
\hline \multicolumn{9}{|c|}{$\begin{array}{l}\text { EGFRIHC } \\
\text { Exon19del } \\
\text { (E746-A750) }\end{array}$} \\
\hline Positive & 12 & 0 & 0 & 0 & 0 & 0 & $2^{\mathrm{a}}$ & 14 \\
\hline Negative & $7^{\mathrm{a}}$ & 2 & 2 & 10 & 2 & 1 & 153 & 177 \\
\hline Total & 19 & 2 & 2 & 10 & 2 & 1 & 155 & 191 \\
\hline
\end{tabular}

Abbreviations: Del, deletion; IHC, immunohistochemistry; ins, insertion; RT-PCR, real-time PCR; WT, wild type.

${ }^{\mathrm{a}}$ Samples further described in Tables 4 and 5.

Table 3 Overview of EGFR exon21 mutations by EGFR IHC and RT-PCR

\begin{tabular}{|c|c|c|c|c|c|c|c|c|}
\hline & \multicolumn{8}{|c|}{$R T-P C R$} \\
\hline & Exon 19del & Exon 20ins & $G 719 X$ & $L 858 R$ & $L 861 Q$ & S768I & $W T$ & Total \\
\hline \multicolumn{9}{|l|}{$\begin{array}{l}\text { EGFR IHC } \\
\text { Exon21 } \\
\text { (L858R) }\end{array}$} \\
\hline Positive & 0 & 0 & 1 & 8 & 0 & 0 & $3^{\mathrm{a}}$ & 12 \\
\hline Negative & 19 & 2 & 1 & $2^{\mathrm{a}}$ & $2^{\mathrm{a}}$ & 1 & 152 & 179 \\
\hline Total & 19 & 2 & 2 & 10 & 2 & 1 & 155 & 191 \\
\hline
\end{tabular}

Abbreviations: Del, deletion; IHC, immunohistochemistry; ins, insertion; RT-PCR, real-time PCR; WT, wild type.

${ }^{a}$ Samples further described in Tables 4 and 5.

False negative and false positive cases were summarized in Table 4 (adenocarcinoma cases) and Table 5 (squamous cell carcinoma cases). False negative cases included three specimens, which were diagnosed as squamous cell carcinomas on morphology as well as by positivity for P40 and negative staining for TTF1 by immunohistochemistry. Two other false negative used blocks from different locations (1: the block for RT-PCR was from the thoracic lymph node station $4 \mathrm{R}$ and for immunohistochemistry from the primary tumor in the left lung lobe, 2: the block for RT-PCR was from the primary tumor in the left lung lobe and for immunohistochemistry from pleura (clot block)). In two cases of adenocarcinoma, a L861Q mutation in exon21 was detected by RT-PCR and immunohistochemistry was negative. Interestingly, in one case of adenocarcinoma, in which an exon19 mutation was detected by RT-PCR, nonspecific staining of smooth muscle tissue and vascular endothelia was observed using the mutation-specific antibody against exon19.

Of false positive cases, one (no. 11 in Table 4) had staining score $=300$. Immunohistochemistry and RT-PCR were performed on the same block. This tumor was diagnosed as an adenocarcinoma on morphology and immunohistochemistry, and was from a never-smoking female. The other four false positive (two squamous cell carcinomas and two adenocarcinomas) showed heterogeneous immuno- histochemical staining of the malignant tumor cells (staining scores $20,70,100,125$ ).

RT-PCR detected two exon18 and three exon20 mutations. One of these had staining score $=10$ (staining of exon21 antibody). RT-PCR found this tumor being exon18 mutated (G719X).

The specific staining of the mutation-specific antibodies was mutually exclusive (Figure 1). Nonspecific diffuse cytoplasmic staining by the exon 19 antibody was observed in smooth muscle tissue $(n=15)$ and vascular endothelia $(n=3)$. For the exon21 antibody, nonspecific cytoplasmic staining not related to any cell type was seen $(n=33)$. These stainings were evaluated as immunohistochemistry negative (Figure 2).

The DAKO antibody against EGFR variantIII showed membranous and cytoplasmic staining of malignant tumor cells in 154 samples (staining score20-300) with no correlation to EGFR mutation status determined by RT-PCR or to immunohistochemistry using mutation-specific antibodies (data not shown).

\section{Specificity and Sensitivity of EGFR Immunohistochemistry}

Specificity of exon19 antibody was 98.8\% (95\% confidence interval $=95.9-99.9 \%)$ and sensitivity was $63.2 \%$ (95\% confidence interval $=38.4-83.7 \%$ ). 
Table 4 Presentation of discrepant detection of exon19 and exon21 mutations by EGFR IHC and RT-PCR in adenocarcinomas

\begin{tabular}{|c|c|c|c|c|c|c|}
\hline No. & & $R T-P C R$ & Specimen & $\begin{array}{l}\text { Tumor cell } \\
\text { number }\end{array}$ & $\begin{array}{l}\text { Same } \\
\text { location for } \\
\text { both methods }\end{array}$ & Comments \\
\hline 1 & $\begin{array}{l}\text { EGFR IHC, exon19 } \\
\text { Negative }\end{array}$ & Positive & Histological & $>400$ & No & $\begin{array}{l}\text { RT-PCR: histological sample from a lymph } \\
\text { node, station } 4 \text { R. EGFR IHC: histological } \\
\text { specimen from left lung lobe. Treated with TKI } \\
\text { Erlotinib (partial response). }\end{array}$ \\
\hline 2 & Negative & Positive & Cytological & $>400$ & No & $\begin{array}{l}\text { RT-PCR: histological sample from left lung } \\
\text { lobe. EGFR IHC: clot from pleura. Treated with } \\
\text { TKI Gefitinib (partial response). }\end{array}$ \\
\hline 3 & Negative & Positive & Histological & $>400$ & Yes & $\begin{array}{l}\text { Unspecific staining of smooth muscle tissue } \\
\text { and vascular endothelia (IHC). No staining of } \\
\text { malignant tumor cells. Treated with TKI } \\
\text { Gefitinib (partial response). }\end{array}$ \\
\hline 4 & Negative & Positive & Histological & $100-400$ & Yes & $\begin{array}{l}\text { Treated with resection of the lung. No TKI } \\
\text { therapy. }\end{array}$ \\
\hline 5 & $\begin{array}{l}\text { Positive: } 20 \% \text { of malignant } \\
\text { cells with intensity } 1\end{array}$ & Negative & Histological & $>400$ & No & $\begin{array}{l}\text { RT-PCR: clot from right lung lobe. EGFR IHC: } \\
\text { histological sample from lymph node, station } 7 \\
\text { Treated with TKI Erlotinib, response unknown. }\end{array}$ \\
\hline 6 & $\begin{array}{l}\text { EGFR IHC, Exon } 21 \\
\quad \text { Negative }\end{array}$ & Positive & Cytological & $<100$ & Yes & $\begin{array}{l}\text { IHC on block, RT-PCR on slide, same location } \\
\text { Few tumor cells. }\end{array}$ \\
\hline 7 & Negative & Positive & Histological & $100-400$ & Yes & $\begin{array}{l}\text { Mutation of exon } 21 \text { being L861Q, not } \\
\text { detectable in EGFR IHC, which stains only the } \\
\text { L858R mutation of exon } 21 \text {. Treated with } \\
\text { resection of the lung. }\end{array}$ \\
\hline 8 & Negative & Positive & Cytological & $100-400$ & Yes & $\begin{array}{l}\text { Mutation of exon } 21 \text { being L861Q, not } \\
\text { detectable in EGFR IHC, which stains only the } \\
\text { L858R mutation of exon21. Treated with TKI } \\
\text { Erlotinib (progressive disease). }\end{array}$ \\
\hline 9 & Negative & Positive & Cytological & $<100$ & Yes & Female. Treated with chemotherapy. \\
\hline 10 & $\begin{array}{l}\text { Positive: } 35 \% \text { malignant } \\
\text { cells of intensity } 310 \% \\
\text { malignant cells of intensity2 }\end{array}$ & Negative & Cytological & $>400$ & Yes & $\begin{array}{l}\text { Heterogeneous EGFR IHC. Ex-smoker for } 30 \\
\text { years ( } 18 \text { pack years). Treated with TKI } \\
\text { Erlotinib (stable disease). }\end{array}$ \\
\hline 11 & $\begin{array}{l}\text { Positive: } 100 \% \text { malignant } \\
\text { cells of intensity } 3\end{array}$ & Negative & Histological & $100-400$ & Yes & Female. Never-smoker. \\
\hline
\end{tabular}

Abbreviations: EGFR, epidermal growth factor receptor; IHC, immunohistochemistry; RT-PCR, real-time quantitative PCR; TKI, tyrosine kinase inhibitor.

Specificity of exon21 antibody was $97.8 \%$ $(95 \%$ confidence interval $=94.4-99.4 \%)$ and sensitivity was $80.0 \%$ (95\% confidence interval $44.4-$ $97.5 \%)$.

A sub-analysis was performed on samples on which RT-PCR and immunohistochemistry were performed on material from the same block. No significant difference in specificity or sensitivity compared with results for the whole material was demonstrated (data not shown).

\section{Discussion}

In this study, specificity of the mutation-specific antibodies against deletions in exon19 and mutations in exon21 was high. However, sensitivity was low, especially for exon19 deletions, and thus these antibodies are not ready for use in screening for EGFR mutations in patients with NSCLC.
The high specificity observed for both antibodies is in line with the literature, where specificity of exon19 mutations ranged from 92 to $100 \%$ and for exon21 mutations from 97 to $100 \% .{ }^{14-22}$ All these studies used the same mutation-specific antibodies from Cell Signaling Technology and the methods were comparable. Simonetti et al. found specificity of $100 \%$ for both antibodies in 78 unselected Caucasian patients. ${ }^{17}$ Brevet et al. found specificity of $95 \%$ for the exon19 antibody and $99 \%$ for the exon21 antibody in 194 selected Caucasian patients. ${ }^{20}$ Thus, excellent specificity of immunohistochemistry using the two mutation-specific antibodies is clearly demonstrated.

The low sensitivity for exon19 deletions is mostly explained by the fact that the exon19 antibody only detects the most common deletion of exon19 (deletion E746-A750). This deletion is of 15 base pairs and represents $50-65 \%$ of all exon19 deletions. ${ }^{21}$ However, deletions of 9, 12, 16, 18, and 24 base-pairs have been identified, each producing a 
Table 5 Presentation of discrepant detection of exon19 and exon21 mutations by EGFR IHC and RT-PCR in squamous cell carcinomas

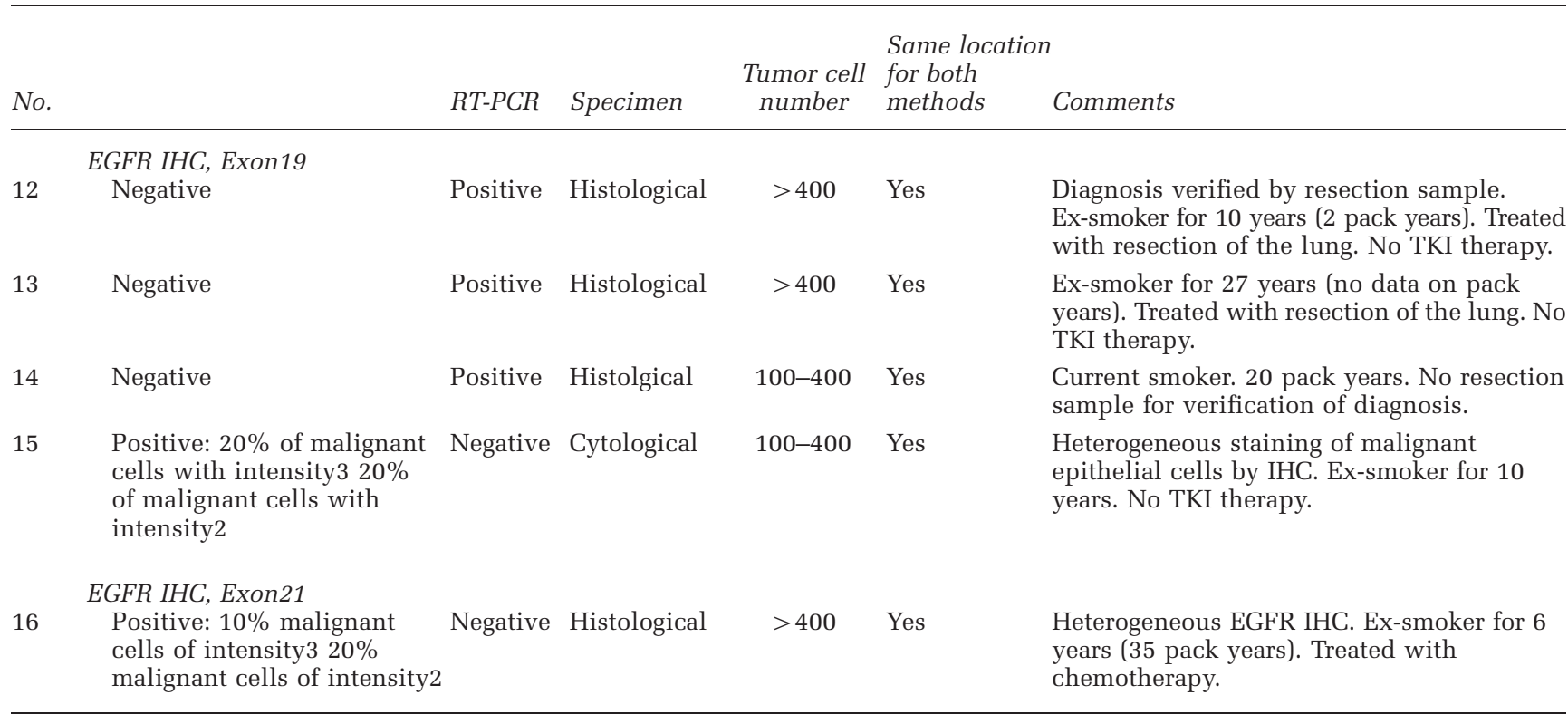

Abbreviations: EGFR, epidermal growth factor receptor; IHC, immunohistochemistry; RT-PCR, real-time quantitative PCR; TKI, tyrosine kinase inhibitor.

slightly different epitope not detectable by the exon19 antibody. ${ }^{21}$ Previous studies using the mutation-specific antibodies from Cell Signaling Technology have found sensitivity ranging from 23 to $80 \%$ for exon 19 deletions and 36 to $100 \%$ for exon21 mutations. ${ }^{14-22}$ These studies used different scores for intensity and cutoff point for positivity making comparisons between the individual studies difficult, and standardization is warranted. ${ }^{23}$

No gold standard method is approved for detecting EGFR mutations in NSCLC. In the present study, RT-PCR was chosen as reference method, as this method was used in the IPASS study, which was the only study demonstrating correlation between EGFR mutations and response of EGFR tyrosine kinase inhibitors in NSCLC, when this study was initiated. ${ }^{7}$

Three false negative cases (immunohistochemistry negative, RT-PCR positive) were demonstrated in tumors classified as squamous cell carcinoma on morphology as well as on immunohistochemistry. EGFR mutations are previously demonstrated in squamous cell carcinomas. ${ }^{26}$ However, an ongoing debate is whether these tumors are incomplete sampling of adenosquamous carcinomas or poorly differentiated adenocarcinomas morphologically mimicking squamous cell carcinomas. ${ }^{26}$

In two cases of adenocarcinoma, mutations were demonstrated by RT-PCR, whereas immunohistochemistry was negative for both antibodies. In these cases, the analyzed block for RT-PCR analysis was from a different location than the block used for immunohistochemistry, as no material was left for immunohistochemistry after cutting material for RTPCR. A heterogeneous distribution of EGFR muta- tion within the same tumor and between the primary tumor and its metastases has been demonstrated. ${ }^{27}$ Whether this might be the reason for the discrepant results from the EGFR analyses in these cases is unknown.

Two less common activating L861Q mutations of exon $21,{ }^{28}$ which is not stainable by the exon21 antibody, were demonstrated by RT-PCR. Likewise, the activating mutations of exon18 and the resistant mutation of exon20 (T790M) are not detected by the mutation-specific antibodies.

In one case of adenocarcinoma, in which RT-PCR demonstrated mutation in exon19, staining of vascular endothelia and smooth muscle cells was demonstrated by the exon19 antibody. Formalin fixation of DNA can cause PCR artifacts during amplification, which might be detected as mutations. ${ }^{29}$ Whether this might be the case in this sample remains speculative.

Of the five false positive (immunohistochemistry positive RT-PCR negative) cases, one was an adenocarcinoma from a never-smoking female with staining score $=300$ (no. 11 in Table 4). Immunohistochemistry and RT-PCR were performed on the same block. Unfortunately, no tyrosine kinase inhibitor treatment was initiated, and whether RTPCR or immunohistochemistry demonstrated the true EGFR status for this patient is unknown.

Four false positive cases showed heterogeneous immunohistochemical staining of the malignant tumor cells (staining scores 20, 70, 100, 125). Three of these used same blocks for immunohistochemistry and RT-PCR, suggesting EGFR mutations might have appeared in the block after tumor tissue had been cut for RT-PCR. 


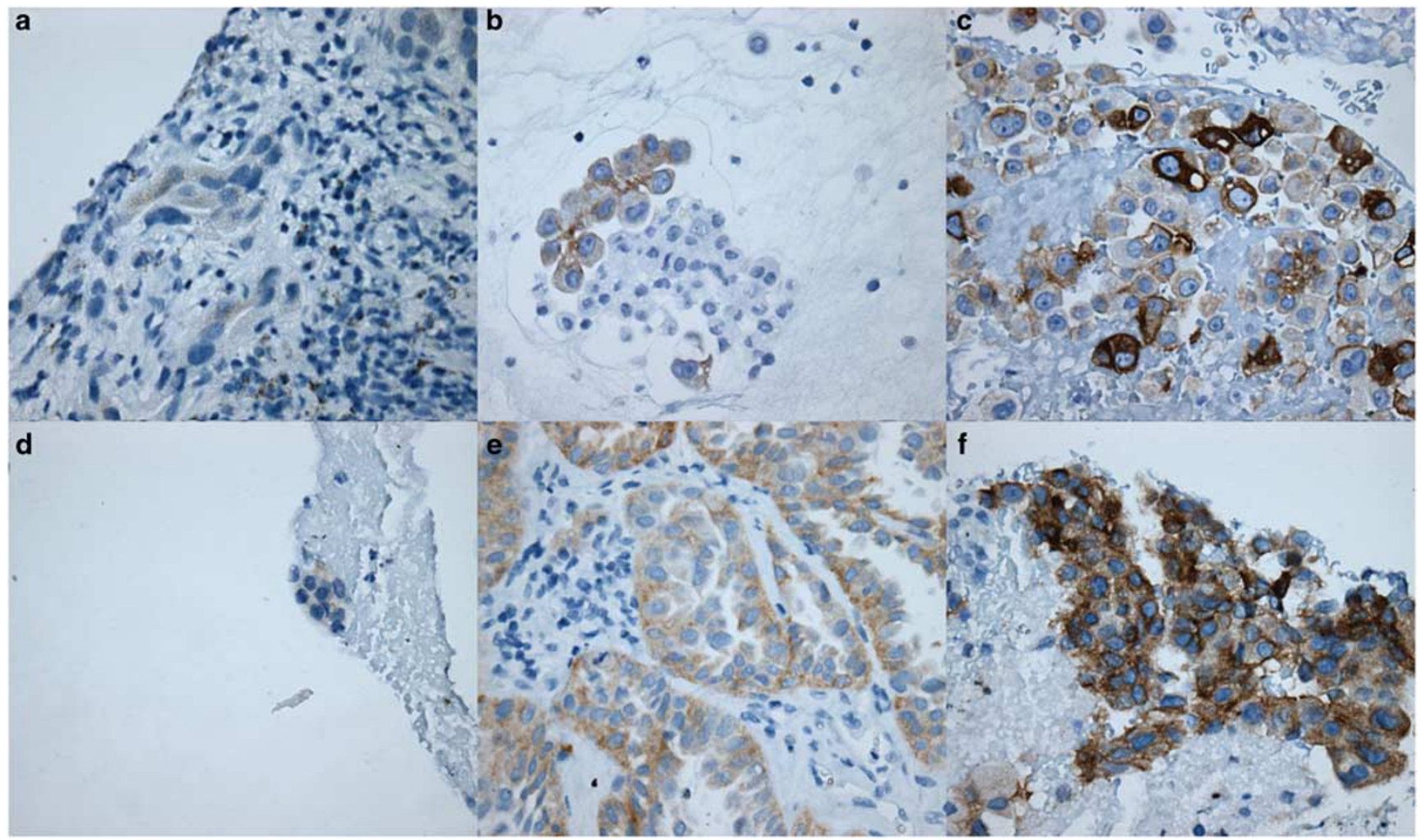

Figure 1 Presentation of immunohistochemical staining of mutation-specific antibodies from Cell Signaling Technology (Boston, USA). (a) Immunohistochemical staining of exon19 antibody, weak intensity (1), $\times 400$ magnification. (b) Immunohistochemical staining of exon19 antibody, moderate intensity (2), × 400 magnification. (c) Immunohistochemical staining of exon19 antibody, moderate (2) and strong intensity (3), × 400 magnification. (d) Immunohistochemical staining of exon21 antibody, weak intensity (1), $\times 400$ magnification. (e) Immunohistochemical staining of exon21 antibody, moderate intensity (2), $\times 400$ magnification. (f) Immunohistochemical staining of exon21 antibody, strong intensity (3), × 400 magnification.

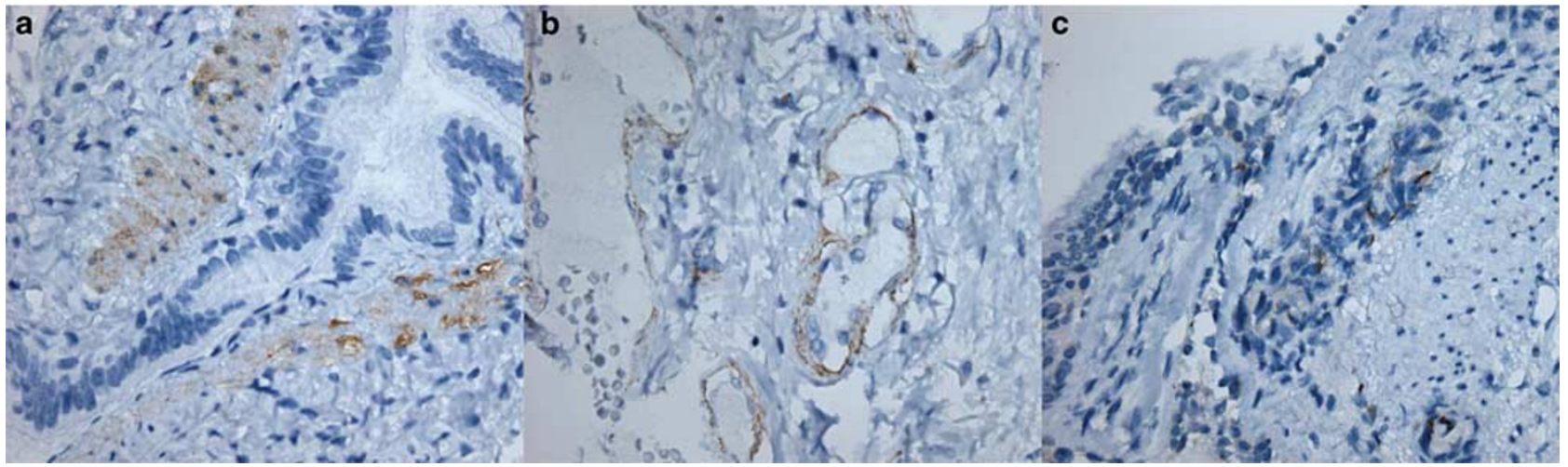

Figure 2 Presentation of nonspecific staining of mutation-specific antibodies from Cell Signaling Technology (Boston, USA). (a) Nonspecific staining of exon19 antibody (staining of smooth muscle cells), $\times 400$ magnification. (b) Nonspecific staining of exon19 antibody (staining of vascular endothelia), $\times 400$ magnification. (c) Nonspecific staining of exon21 antibody, $\times 400$ magnification.

Selecting the optimal test for identifying patients with NSCLC to EGFR tyrosine kinase inhibitors is dependent of several factors. Of cause, accuracy and reproducibility of the test are essential. Other factors such as cost, turnaround time, and the amount of tissue necessary for performing the test should be taken into account.

RT-PCR is able to detect as little as $1 \%$ mutated malignant epithelial cells and no quantification is available for this test. The therapeutic relevance in tumors being positive in a rather small fraction of malignant tumor cells has been debated. ${ }^{23}$ It is observed that high abundance of EGFR mutations (defined by mutations detected by DNA sequencing and ARMS) showed significant longer progressionfree survival than low abundance of EGFR mutations (defined by mutations detected by ARMS but not DNA sequencing). Such selection of patients 
with NSCLC promoted a better treatment strategy for both high and low EGFR mutations abundant tumors. ${ }^{30-33}$ Further quantification of staining scores in mutation-positive NSCLC has been assessed, and high staining score has been associated with a significant longer progression-free survival in mutation-positive patients as compared with low staining score. ${ }^{31}$ A study in which the randomization to EGFR tyrosine kinase inhibitors would be based on the method used for demonstrating an activating EGFR mutation might give clinical relevant information regarding the significance of the amount of EGFR-mutated cells.

In conclusion, high specificity of mutationspecific antibodies against exon19 and exon21 mutations was demonstrated. However, sensitivity was low, especially for exon19 deletions, and thus these antibodies cannot yet be used as screening or diagnostic method for determining EGFR status in NSCLC. Refinement of sensitivity for mutation-specific antibodies is warranted to improve immunohistochemical diagnosis of EGFR mutations in these tumors.

\section{Acknowledgments}

We thank Jane Andersen and Camilla Hansen for excellent laboratory assistance. We also thank Torsten Skov for excellent advice with statistical analysis. Anna-Louise Bondgaard was financially supported by a scholarship donated by Danish Cancer Society during her research year. The study was supported by foundations of Frimodts, Harboe (Dako), Agnes and Poul Friis, Aksel, and Vetsera Meyer Nielsen, Lykfeldt and MD Johan and Lise Boserup.

\section{Disclosure/conflict of interest}

The authors declare no conflict of interest.

\section{References}

1 Mok TS, Wu YL, Thongprasert S, et al. Gefitinib or carboplatin-paclitaxel in pulmonary adenocarcinoma. N Engl J Med 2009;361:947-957.

2 Lynch TJ, Bell DW, Sordella R, et al. Activating mutations in the epidermal growth factor receptor underlying responsiveness of non-small-cell lung cancer to gefitinib. N Engl J Med 2004;350:2129-2139.

3 Hirsch FR, Varella-Garcia M, Bunn PA Jr, et al. Molecular predictors of outcome with gefitinib in a phase III placebo-controlled study in advanced non-small-cell lung cancer. J Clin Oncol 2006;24: 5034-5042.

4 Mitsudomi T, Morita S, Yatabe Y, et al. Gefitinib versus cisplatin plus docetaxel in patients with non-smallcell lung cancer harbouring mutations of the epidermal growth factor receptor (WJTOG3405): an open label, randomised phase 3 trial. Lancet Oncol 2010;2: 121-128.

5 Sequist LV, Martins RG, Spigel D, et al. First-line gefitinib in patients with advanced non-small-cell lung cancer harboring somatic EGFR mutations. J Clin Oncol 2008;26:2442-2449.

6 Tamura K, Okamoto I, Kashii T, et al. Multicentre prospective phase II trial of gefitinib for advanced nonsmall cell lung cancer with epidermal growth factor receptor mutations: results of the West Japan Thoracic Oncology Group trial (WJTOG0403). Br J Cancer 2008;98:907-914.

7 Fukuoka M, Wu YL, Thongprasert S, et al. Biomarker analyses and final overall survival results from a phase III, randomized, open-label, first-line study of gefitinib versus carboplatin/paclitaxel in clinically selected patients with advanced non-small-cell lung cancer in Asia (IPASS). J Clin Oncol 2011;29:2866-2874.

8 Tsao MS, Sakurada A, Cutz JC, et al. Erlotinib in lung cancer-molecular and clinical predictors of outcome. N Engl J Med 2005;353:133-144.

9 Thunnissen E, Kerr KM, Herth FJ, et al. The challenge of NSCLC diagnosis and predictive analysis on small samples. Practical approach of a working group. Lung Cancer 2012;76:1-18

10 Tsao MS, Sakurada A, Ding K, et al. Prognostic and predictive value of EGFR tyrosine kinase domain mutation status and gene copy number for adjuvant chemotherapy in non-small cell lung cancer. J Thorac Oncol 2011;6:139-147.

11 Helland AA, Skaug HM, Kleinberg L, et al. EGFR gene alterations in a Norwegian cohort of lung cancer patients selected for surgery. J Thorac Oncol 2011; 6:947-950.

12 Rosell R, Moran T, Queralt C, et al. Screening for epidermal growth factor receptor mutations in lung cancer. N Engl J Med 2009;361:958-967.

13 Skov BG, Hogdall E, Clementsen $\mathrm{P}$, et al. The prevalence of EGFR mutations in non-small cell lung cancer in an unselected Caucasian population. Submitted to Clinical Lung Cancer (e-pub ahead of print).

14 Nakamura $\mathrm{H}$, Mochizuki A, Shinmyo $\mathrm{T}$, et al. Immunohistochemical detection of mutated epidermal growth factor receptors in pulmonary adenocarcinoma. Anticancer Res 2010;12:5233-5237.

15 Kozu Y, Tsuta K, Kohno T, et al. The usefulness of mutation-specific antibodies in detecting epidermal growth factor receptor mutations and in predicting response to tyrosine kinase inhibitor therapy in lung adenocarcinoma. Lung Cancer 2011;73:45-50.

16 Kato Y, Peled N, Wynes MW, et al. Novel epidermal growth factor receptor mutation-specific antibodies for non-small cell lung cancer: immunohistochemistry as a possible screening method for epidermal growth factor receptor mutations. J Thorac Oncol 2010;10: 1551-1558.

17 Simonetti S, Molina MA, Queralt C, et al. Detection of EGFR mutations with mutation-specific antibodies in stage IV non-small-cell lung cancer. J Transl Med 2010;8:135.

18 Kitamura A, Hosoda W, Sasaki E, et al. Immunohistochemical detection of EGFR mutation using mutationspecific antibodies in lung cancer. Clin Cancer Res 2010;16:3349-3355.

19 Kawahara A, Yamamoto C, Nakashima K, et al. Molecular diagnosis of activating EGFR mutations in non-small cell lung cancer using mutation-specific 
antibodies for immunohistochemical analysis. Clin Cancer Res 2010;16:3163-3170.

20 Brevet M, Arcila M, Ladanyi M. Assessment of EGFR mutation status in lung adenocarcinoma by immunohistochemistry using antibodies specific to the two major forms of mutant EGFR. J Mol Diagn 2010;12: 169-176.

21 Yu J, Kane S, Wu J, et al. Mutation-specific antibodies for the detection of EGFR mutations in non-small-cell lung cancer. Clin Cancer Res 2009;15:3023-3028.

22 Ilie MI, Hofman V, Bonnetaud C, et al. Usefulness of tissue microarrays for assessment of protein expression, gene copy number and mutational status of EGFR in lung adenocarcinoma. Virchows Arch 2010;457: 483-495.

23 Eberhard DA, Giaccone G, Johnson BE. Non-Small-Cell Lung Cancer Working Group. Biomarkers of response to epidermal growth factor receptor inhibitors in NonSmall-Cell Lung Cancer Working Group: standardization for use in the clinical trial setting. J Clin Oncol 2008;26:983-994.

24 Hirsch FR, Dziadziuszko R, Thatcher N, et al. Epidermal growth factor receptor immunohistochemistry: comparison of antibodies and cutoff points to predict benefit from gefitinib in a phase 3 placebo-controlled study in advanced nonsmall-cell lung cancer. Cancer 2008;5:1114-1121.

25 Rüschoff J, Dietel M, Baretton G, et al. HER2 diagnostics in gastric cancer-guideline validation and development of standardized immunohistochemical testing. Virchows Arch 2010;457:299-307.

26 Rekhtman N, Paik PK, Arcila ME, et al. Clarifying the spectrum of driver oncogene mutations in biomarkerverified squamous carcinoma of lung: lack of EGFR/
KRAS and presence of PIK3CA/AKT1 mutations. Clin Cancer Res 2012;18:1167-1176.

27 Park S, Holmes-Tisch AJ, Cho EY, et al. Discordance of molecular biomarkers associated with epidermal growth factor receptor pathway between primary tumors and lymph node metastasis in non-small cell lung cancer. J Thorac Oncol 2009;7:809-815.

28 Sequist LV, Martins RG, Spigel D, et al. First-line gefitinib in patients with advanced non-small-cell lung cancer harboring somatic EGFR mutations. J Clin Oncol 2008;26:2442-2449.

29 Do H, Krypuy M, Mitchell PL, et al. High resolution melting analysis for rapid and sensitive EGFR and KRAS mutation detection in formalin fixed paraffin embedded biopsies. BMC Cancer 2008;8:142.

30 Angulo B, Conde E, Suárez-Gauthier A, et al. A comparison of EGFR mutation testing methods in lung carcinoma: direct sequencing, real-time PCR and immunohistochemistry. PLoS One 2012;7:e43842.

31 Azuma K, Okamoto I, Kawahara A, et al. Association of the expression of mutant epidermal growth factor receptor protein as determined with mutation-specific antibodies in non-small cell lung cancer with progression-free survival after gefitinib treatment. J Thorac Oncol 2012;1:122-127.

32 Italiano A, Vandenbos FB, Otto J, et al. Comparison of the epidermal growth factor receptor gene and protein in primary non-small-cell-lung cancer and metastatic sites: implications for treatment with EGFR-inhibitors. Ann Oncol 2006;17:981-985.

33 Gupta R, Dastane AM, Forozan F, et al. Evaluation of EGFR abnormalities in patients with pulmonary adenocarcinoma: the need to test neoplasms with more than one method. Mod Pathol 2009;1:128-133. 